\title{
Cross metathesis of (-)- $\beta$-pinene, (-)-limonene and terpenoids derived from limonene with internal olefins
}

Luciana Sarmento Fernandes, ${ }^{\mathrm{a}, \mathrm{b}}$ Dalmo Mandelli, ${ }^{\mathrm{b}}$ Wagner A. Carvalho, ${ }^{\mathrm{b}}$ Elsa Caytan, ${ }^{\mathrm{a}}$ Cédric Fischmeister, ${ }^{\text {a }}$ Christian Bruneau ${ }^{\mathrm{a} *}$

a Univ Rennes, CNRS, ISCR (Institut des Sciences Chimiques de Rennes) - UMR6226, 35000 Rennes, France

${ }^{\mathrm{b}}$ Centro de Ciências Naturais e Humanas, Universidade Federal do ABC, Santo André, Brazil

\begin{abstract}
The straightforward functionalization of sterically demanding $\alpha, \alpha$-disubstituted double bonds of $\beta$-pinene, (-)-limonene and (-)-limonene terpenoids has been achieved via cross metathesis with internal olefins. The reactions are catalyzed by second generation ruthenium catalysts in dimethyl carbonate as green solvent or under neat conditions. This transformation provides a clean process for the access to functionalized bulky cyclic terpenes where the terminal double bond generates a trisubstituted olefin.
\end{abstract}

Keywords: Cyclic terpenes, Olefin metathesis, Ruthenium catalyst, Sustainable chemistry

\section{Introduction}

Terpenes and terpenoids represent a wide class of natural products including linear molecules, cyclic structures and even polymers, derived from the isoprene unit [1]. Some of them are very abundant in nature, others are produced in huge amount in agrochemical industry. For instance the world production of turpentine containing mainly cyclic terpenes is estimated at 350.000 tons/year [2] and the production of limonene from the fruit juice industry could reach 65.000 tons/year [3]. Beside the current applications of these natural and renewable products in the fields of fragrances and flavors in cosmetic and food industry [1], their transformation into value-added products via sustainable processes is of highest economical interest. Oxidation, epoxidation, hydroformylation, hydrogenation, isomerization, rearrangement of terpenes, most of these catalytic transformations taking advantage of the presence of at least one carbon-carbon double bond in the initial molecule have been successfully achieved [4-8]. Olefin metathesis is also a clean catalytic transformation with high potential for direct modification of unsaturated natural products that has been applied to fatty acid derivatives [9,10], phenylpropanoids [11] 
and terpenes [12] mainly in the presence of ruthenium catalysts. Cross metathesis is especially well adapted for the incorporation of a functional group into acyclic monoterpenes equipped with a terminal or prenyl double bond with cross metathesis partners featuring a terminal double bond such as acrylic [13-15] and allylic substrates [16]. On the other hand, to our knowledge, only one example of cross metathesis of a cyclic terpene (limonene) with a terminal olefin (hex1-ene) in the presence of the second generation Grubbs catalyst Ru1 [17], has been reported [18]. However, cross metathesis of bulky cyclic terpenes such as $\beta$-pinene and camphene has been performed in satisfactory yields with an internal olefin, namely a $N, O$-protected prenylglycine, in the presence of the second generation Hoveyda catalyst Ru2 [19,20]. It must be noted that the favorable behavior of internal with respect to terminal olefins was also observed during cross metathesis of the same prenylglycine substrate with exomethylenecyclohexane derivatives substituted in $\alpha$-position of the methylene double bond [21]. Another seminal result revealed that the non-functionalized internal 3-methylpent-2-ene was an effective partner for the cross metathesis with $\beta$-pinene under neat conditions in the presence of the second generation Grubbs catalyst [22]. Degradation of natural rubber via cross-metathesis with pure limonene or mandarin oil (mainly containing limonene) using Grubbs catalysts represent an interesting application in polymer chemistry [23]. Recently, we have shown that the utilization of the internal double bond of a symmetrical cross metathesis partner such as dimethyl fumarate, dimethyl maleate, fumaronitrile and 1,4-diacetoxybut-2-ene was very efficient and selective for the functionalization of $\beta$-pinene and limonene in the presence of ruthenium catalysts [24]. We now report that the cross metathesis with $\beta$-pinene and limonene can be applied to other internal olefins including 2-methylbut-2-ene and 1,4-dichlorobut-2-ene. The influence of oxygenated functional groups in the terpene partner has also been evaluated with terpenoids derived from limonene bearing a ketone and an epoxide group.

\section{Experimental}

All metathesis reactions were carried out with exclusion of air using Schlenk tube techniques. Dimethyl carbonate (DMC) was distillated and stored over activated 3 Å molecular sieves. NMR spectra were recorded at $400 \mathrm{MHz}$ for ${ }^{1} \mathrm{H}$ and $100 \mathrm{MHz}$ for ${ }^{13} \mathrm{C}$ on a Bruker Ascend - Av III spectrometer. Chemical shifts are given in ppm vs TMS using the residual solvent $\left(\mathrm{CDCl}_{3}\right)$ signal as reference. Reactions were monitored using a Shimadzu 2014 gas 
chromatograph equipped with a $30 \mathrm{~m}$ x $0.25 \mathrm{~mm}$ x $0.25 \mu \mathrm{m}$ Equity TM - 1 Fused Silica capillary column. Pure products were obtained by column chromatography on silica gel (Merck Silica Gel 60) or alumina using mixtures of heptane and ethyl acetate as the eluent. Products were further analyzed by GC-MS on a Shimadzu QP2010S apparatus.

The indexations of signals in ${ }^{1} \mathrm{H}$ and ${ }^{13} \mathrm{C}$ NMR were based on COSY, HSQC and HMBC sequences and NOESY (800 ms mixing time) for structure determination.

The commercially available substrates were used as received. (-)- $\beta$-Pinene (98 \%) was purchased from Acros Organics. The other terpene derivatives (-)-limonene (96\%), (+)-carvone (98\%), (+)-trans-limonene epoxide (97\%) were supplied by Aldrich. The cross metathesis partners 2-methylbut-2-ene (>95\%), dimethyl maleate (97\%) and cis-1,4-dichlorobut-2-ene (97\%) were purchased from Aldrich. The cross metathesis reactions were investigated with the commercially available second generation Hoveyda-Grubbs ruthenium catalyst Ru2, the Zhan catalyst Ru3 and Ru4 (Scheme 1). Ru2 CAS 301224-40-8, Ru4 CAS 1025728-57-7 were offered by Umicore and Ru3 CAS 918870-76-5 was supplied by Strem.

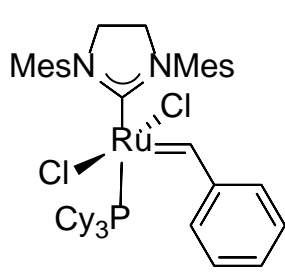

Ru1

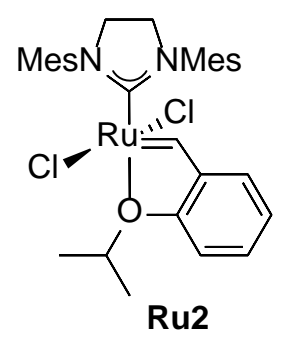

Ru2

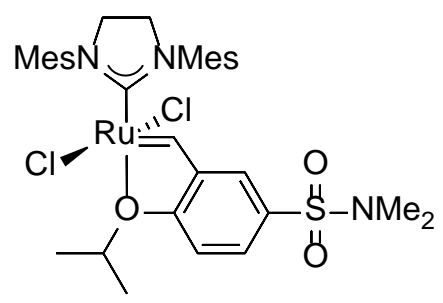

Ru3

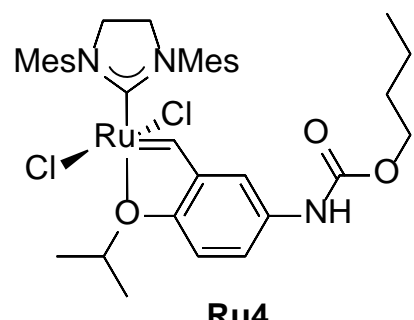

Ru4

Mes: 2,4,6-trimethylphenyl (mesityl)

Scheme 1. Various ruthenium catalysts used in this study

\section{Results and discussion}

\subsection{Cross metathesis of $\beta$-pinene and (-)-limonene with 2-methylbut-2-ene}

After demonstrating the efficient cross metathesis of sterically hindered cyclic terpenes with symmetrical maleate and fumarate bearing an electron-deficient carbon-carbon double bond [24], we attempted the cross metathesis of (-)- $\beta$-pinene $\mathbf{1}$ and (-)-limonene $\mathbf{2}$ with the purely aliphatic 2-methylbut-2-ene 3 with various ruthenium catalysts (Scheme 2). 


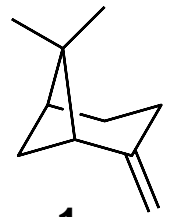

1<smiles>C=C(C)[C@H]1CC=C(C)CC1</smiles>

2<smiles>[C+]C=C(C)C</smiles>

Ru2 or Ru3

$40^{\circ} \mathrm{C}, 15 \mathrm{~h}$

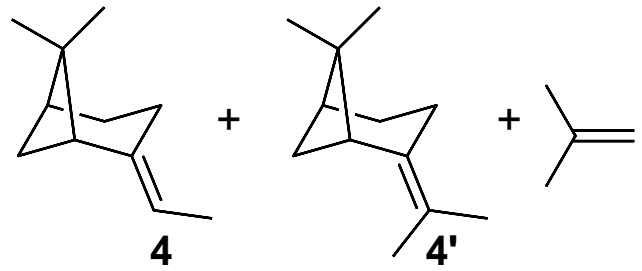

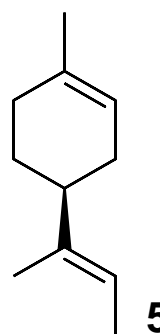

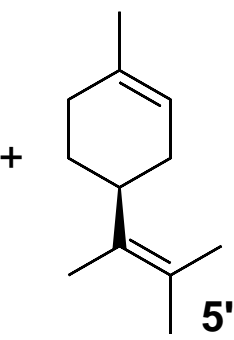

Scheme 2. Cross metathesis of (-)- $\beta$-pinene 1 and (-)-limonene 2 with 2-methylbut-2-ene 3

In addition to the expected $E$ - and $Z$-stereoisomers, the utilization of a non-symmetrical internal olefin might generate two families of products (4, 4' and 5, 5’). The reactions were investigated with the two second generation ruthenium catalysts $\mathbf{R u 2}$ and $\mathbf{R u 3}$. They were performed in dimethyl carbonate (DMC) as a green solvent [25] or without solvent at $40{ }^{\circ} \mathrm{C}$ with various concentrations of reagents and catalyst loadings. When the reaction was carried out in DMC, a fourfold excess of $\mathbf{3}$ with respect to the terpene was introduced and hexadecane was used as internal standard to evaluate the conversion of the terpene and yield of product by gas chromatography. When the reaction was performed under neat conditions, an excess of 13 equivalents of $\mathbf{3}$ with respect to the terpene was used. The first experiments were carried out at $40{ }^{\circ} \mathrm{C}$ in DMC with 2.5 and 5 mol\% of catalysts Ru2 and Ru3 during 15 h (Table 1).

Under these conditions, good conversions were obtained but they were still limited to $78 \%$ with $\beta$-pinene 1 and 70\% with limonene 2 and. Because the final products differ from the starting terpene by only one methyl group, it was anticipated that their separation would be difficult and that reaching very high conversion was compulsory to isolate the pure cross metathesis products 4 and 5 . The utilization of 2-methylbut-2-ene 3 both as reagent and solvent led to higher conversions and the addition of the catalyst in two portions allowed to reach $93 \%$ conversion of limonene (entry 14) and full conversion of $\beta$-pinene (entry 5).

In these metathesis reactions, the Hoveyda catalyst Ru2 was slightly more efficient than the Zhan catalyst Ru3. In both cases, the GC analysis of the crude reaction mixture revealed the presence of a major peak (more than 93 area\%), and the proton NMR spectra showed the presence of an ethylenic proton centered at $5.05 \mathrm{ppm}$ for the pinene derivative 4 and $5.25 \mathrm{ppm}$ 
for the limonene product 5. In agreement with this result the GC/MS analysis gave a molecular weight of 150 corresponding to $\mathrm{C}_{11} \mathrm{H}_{18}$.

Table 1. Cross metathesis of terpenes $\mathbf{1}$ and $\mathbf{2}$ with 2-methylbut-2-ene $\mathbf{3}^{\mathrm{a}}$

\begin{tabular}{|c|c|c|c|c|c|}
\hline Entry & $\begin{array}{l}\text { Catalyst } \\
(\mathrm{mol} \%)\end{array}$ & $\begin{array}{l}3 / \mathbf{1} \text { or } \mathbf{3} / \mathbf{2} \\
\text { molar ratio }\end{array}$ & Solvent & $\begin{array}{c}\text { Conversion } \\
\text { (\%) }\end{array}$ & $\begin{array}{c}\text { Yield }^{\mathrm{b}} \\
(\%)\end{array}$ \\
\hline \multicolumn{6}{|c|}{$\beta$-pinene 1} \\
\hline 1 & Ru2 (2.5) & 4 & DMC & 78 & 472 \\
\hline 2 & Ru3 (2.5) & 4 & DMC & 78 & 473 \\
\hline 3 & Ru2 (2.5) & 13 & Neat & 97 & 492 \\
\hline 4 & Ru3 (2.5) & 13 & Neat & 87 & 481 \\
\hline 5 & $\mathbf{R u} 2(2.5+1)^{\mathrm{C}}$ & 13 & Neat & 100 & $497(56)^{d}$ \\
\hline 6 & $\mathbf{R u} 3(2.5+1)^{\mathrm{C}}$ & 13 & Neat & 86 & 482 \\
\hline \multicolumn{6}{|c|}{ (-)-limonene 2} \\
\hline 7 & Ru2 (2.5) & 4 & DMC & 65 & 560 \\
\hline 8 & Ru2 (5.0) & 4 & DMC & 70 & 566 \\
\hline 9 & Ru3 (2.5) & 4 & DMC & 62 & 558 \\
\hline 10 & Ru3 (5.0) & 4 & $\mathrm{DMC}$ & 65 & 561 \\
\hline 11 & Ru3 (5.0) & 13 & Neat & 71 & 567 \\
\hline 12 & Ru2 (5.0) & 13 & Neat & 82 & 576 \\
\hline 13 & Ru3 $(2 \times 2.5)^{\mathrm{C}}$ & 13 & Neat & 76 & 572 \\
\hline 14 & Ru2 $(2 \times 2.5)^{\mathrm{C}}$ & 13 & Neat & 93 & $587(60)^{\mathrm{d}}$ \\
\hline
\end{tabular}

The cross metathesis of the bulky terpenes $\mathbf{1}$ and $\mathbf{2}$ with 2-methylbut-2-ene $\mathbf{3}$ appeared to be regioselective leading to the sole formation of $\mathbf{4}$ and $\mathbf{5}$ featuring a trisubstituted double bond with elimination of isobutene. Products 4' and 5' were not observed (Scheme 2). This regioselectivity is opposite to what was usually observed in cross metathesis with 2-methylbut2-ene. Indeed, this simple trisubstituted olefin has been used efficiently for the introduction of a gem-dimethyl terminal end to monosubstituted double bonds of model compounds [26], and in particular the transformation of allyl into prenyl groups for preparation or modification of 
natural products such as amino acid derivatives [27], flavonoids, coumarines, chromanones, quinolinones [28], in most cases in the presence of the Grubbs second generation catalyst Ru1 under mild conditions. However, in some cases, the reverse regioselectivity was observed during these prenylation reactions [29] leading to up to $15 \%$ of disubstituted double bond starting from a sterically demanding o,o'-diacetoxy allylphenyl structure [29a]. The cleavage of methyl oleate containing an internal double bond via cross metathesis with 2-methylbut-2ene revealed that both regioselectivities could be obtained depending on the nature of the catalyst [30]. The cross-metathesis of a sterically hindered vinylheterocyclic substrate with 2-methylbut-2-ene in the presence of the catalyst Ru2 yielded a mixture of the two regioisomers in a disubstituted/trisubstituted double bond ratio of 2.4/1.0 [31]. The regioselectivity leading to the formation of a 1,2-disubstituted double bond is also exemplified by the cross metathesis of 2-methylbut-2-ene with $n$-butyl acrylate in which the trans- $n$-butyl crotonate was formed in 83\% yield [26] due to the higher reactivity of the alkene than the acrylate to generate a ruthenium ethylidene species, as also observed under stoichiometric conditions from the first generation cyclohexyl ester ruthenium carbene $\mathrm{RuCl}_{2}\left(\mathrm{PCy}_{3}\right)_{2}\left(=\mathrm{CHCO}_{2} \mathrm{Cy}\right)$ and 2-methyl-1pentene [32]. The above examples reveal that the formation of gem-dimethyl olefins is favoured starting from terminal olefins without bulky neighbouring groups, typically allylic fragments, whereas the introduction of steric hindrance, which result in very constrained ruthenacyclobutane intermediates, or electron deficiency at the cross metathesis partner, make the other regioselectivity possible and sometimes preponderant.

Our results are also in line with the calculations of Tlenkopatchev, who predicted that in olefin cross metathesis of $\beta$-pinene with trisubstituted olefins the less substituted ruthenium carbene ( $\left[\mathrm{Ru}=\mathrm{CHMe}\right.$ as compared to $\left[\mathrm{Ru}=\mathrm{CMe}_{2}\right.$ in this case) was the most reactive [22]. The reverse regioselectivity would lead to the formation of a tetrasubstituted double bond with a bulky environment, which is also less favorable. It can be noted that the selectivity in the cross metathesis of $\beta$-pinene with $\mathbf{3}$ was much higher with the Hoveyda catalyst $\mathbf{R u} \mathbf{2}$ than in the reaction of $\beta$-pinene with ( $Z$ )-3-methyl-2-pentene in the presence of the Grubbs catalyst Ru1, which led to a mixture of the two regioisomers in a trisubstituted/tetrasubstituted ratio of 58:16 [22]. The stereochemistry of the created double bonds was determined by NMR and it was found that the $E$-isomers $\mathbf{4}$ and $\mathbf{5}$ were the major products. The stereochemistry was determined using 1D gradient selective NOESY and NOESY, respectively (Figure 1) (see ESI). The very high selectivity in favor of the $E$-isomers was probably due to the presence of a large excess of $\mathbf{3}$ and high conversion, which promoted secondary cross metathesis of $\mathbf{4}$ and $\mathbf{5}$ with $\mathbf{3}$ in the 
presence of the second generation ruthenium catalyst leading to isomerization into the thermodynamically favored $E$-isomers and therefore to an increased E-stereoselectivity, as observed in other cases of cross metathesis [33].
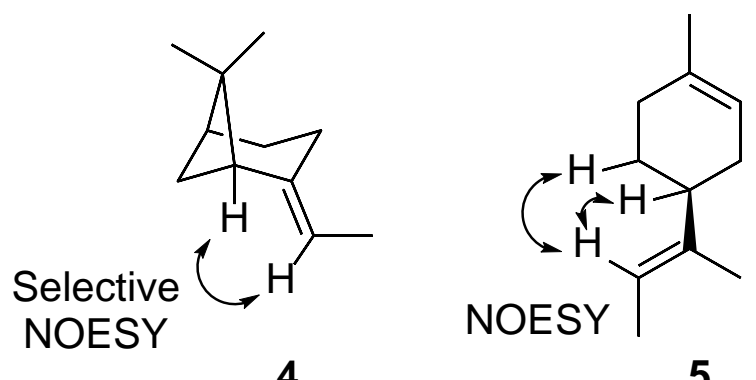

4

5

Figure 1. Determination of structures of $\mathbf{4}$ and $\mathbf{5}$ by NOESY experiments

\subsection{Cross metathesis of limonene-derived terpenoids with dimethyl maleate}

The cross metathesis of (+)-carvone 6 and (+)-trans-limonene epoxide $\mathbf{7}$ with dimethyl maleate was attempted with the reaction conditions previously established with $\beta$-pinene $\mathbf{1}$ and (-)-limonene 2 [24]. It must be noted that in this case the reactions carried out without solvent were also productive but did not improve the results. The reactions were thus carried out in DMC with a concentration of terpenoid of $0.74 \mathrm{~mol} / \mathrm{L}$ at $100^{\circ} \mathrm{C}$ for $15 \mathrm{~h}$ with a fourfold excess of dimethyl maleate (Scheme 3).<smiles>C=C(C)[C@H]1CC=C(C)C(=O)C1</smiles>

6<smiles>C=C(C)[C@@H]1CC[C@@]2(C)O[C@H]2C1</smiles><smiles>COC(=O)/C=C\C(=O)OC</smiles>

8<smiles>COC(=O)/C=C\C(=O)OC</smiles>

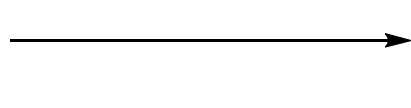

Ru2, Ru3 or Ru4 DMC, $100^{\circ} \mathrm{C}, 15 \mathrm{~h}$

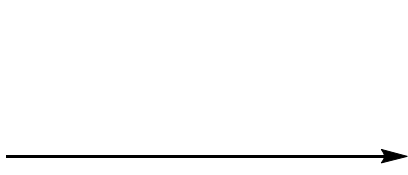<smiles>COC(=O)/C=C(\C)[C@H]1CC=C(C)C(=O)C1</smiles><smiles>COC(=O)/C=C(\C)[C@H]1CC[C@@]2(C)O[C@H]2C1</smiles>

Scheme 3. Cross metathesis of (+)-carvone 6 and (+)-trans-limonene epoxide 7 with dimethyl maleate $\mathbf{8}$ 
From (+)-carvone 6, conversions of about 50\% were obtained with Ru2 and Ru4 [34] with a catalyst loading of $5 \mathrm{~mol} \%$ (Table 2). The addition of the catalyst in two equal portions of $2.5 \mathrm{~mol} \%$ did not improve the result obtained directly with $5 \mathrm{~mol} \%$ of catalyst (entries 2, 3 and 4,5). Ru3 provided low conversions (entries 6, 7). GC analysis of the crude reaction mixture indicated that the two stereoisomers of 9 were formed in a ratio of $66: 34$, which was confirmed by ${ }^{1} \mathrm{H}$ NMR analysis from the integrations of the two signals of the $\mathrm{C}(4)-\mathrm{H}$ protons at centered at 2.8 and $4.4 \mathrm{ppm}$. The ethylenic protons $\mathrm{C}(9)-\mathrm{H}$ of the newly created ethylenic double bond in the two stereoisomers presented the same chemical shift centered at $5.70 \mathrm{ppm}$ but the NOESY spectrum of the mixture showed a correlation between the ethylenic proton in the major isomer with the $\mathrm{C}(4)-\mathrm{H}$ of the carvone ring centered at $2.80 \mathrm{ppm}$, whereas the $\mathrm{C}(4)-\mathrm{H}$ of the minor stereoisomer centered at $4.40 \mathrm{ppm}$ did not show any interaction with the C(9)-H proton. The interaction of the $\mathrm{C}(9)-\mathrm{H}$ with the $\mathrm{C}(10) \mathrm{H}_{3}$ group was observed only in the minor stereoisomer at $1.87 \mathrm{ppm}$. These two observations clearly indicated that the $E$-stereoisomer was the major product.

Table 2. Cross metathesis of (+)-carvone 6 and (+)-trans-limonene epoxide 7 with dimethyl maleate $\mathbf{8}^{\mathrm{a}}$

\begin{tabular}{|c|c|c|c|c|}
\hline Entr & $\begin{array}{l}\text { Catalyst } \\
(\mathrm{mol} \%)\end{array}$ & $\begin{array}{c}\text { Conversion } \\
\text { (\%) }\end{array}$ & $\begin{array}{l}\text { Yield } \\
(\%)\end{array}$ & $\begin{array}{l}E / Z \\
\text { ratio }\end{array}$ \\
\hline \multicolumn{5}{|c|}{$(+)$-carvone 6} \\
\hline 1 & Ru2 (2.5) & 40 & 34 & $67 / 33$ \\
\hline 2 & Ru2 (5.0) & 52 & $49(37)^{\mathrm{c}}$ & $66 / 34$ \\
\hline 3 & Ru2 (2x2.5) ${ }^{\mathrm{b}}$ & 49 & 45 & $65 / 35$ \\
\hline 4 & Ru4 (5.0) & 48 & 43 & $68 / 32$ \\
\hline 5 & Ru4 $(2 \times 2.5)^{b}$ & 48 & $42(37)^{\mathrm{c}}$ & $67 / 33$ \\
\hline 6 & Ru3 (2.5) & 38 & 32 & $67 / 33$ \\
\hline 7 & Ru3 (5) & 37 & 31 & $67 / 33$ \\
\hline \multicolumn{5}{|c|}{$\begin{array}{l}\text { (+)-trans-limonene } \\
\text { epoxide } 7\end{array}$} \\
\hline 8 & Ru2 (5) & 82 & nd & $65 / 35$ \\
\hline 9 & Ru4 (5) & 74 & nd $(13)^{\mathrm{c}}$ & $65 / 35$ \\
\hline
\end{tabular}


${ }^{a}$ General conditions: terpenoid ( $\left.0.7 \mathrm{mmol}\right)$, dimethyl maleate (2.8 mmol, 4 equiv.), DMC ( $\left.1 \mathrm{ml}\right), 100{ }^{\circ} \mathrm{C}, 15 \mathrm{~h}$, conversion and yield were determined by GC using tetradecane as internal standard, nd: not determined. ${ }^{\mathrm{b}}$ first portion $(15 \mathrm{~h})$, second portion $(8 \mathrm{~h}) .{ }^{\mathrm{c}}$ Isolated yield in parenthesis.

From (+)-trans-limonene epoxide 7, Ru2 and Ru4 led to conversions of 82 and 75\%, respectively, into 10. The two cross metathesis stereoisomers were produced in a ratio of 65:35 as shown by GC analysis of the crude mixture. Similarly, NOESY experiments showed that in the major E-isomer, the acrylic $\mathrm{C}(9)-\mathrm{H}$ proton (at $5.65 \mathrm{ppm}$ ) was correlated with protons at $\mathrm{C}(3), \mathrm{C}(4)$ and $\mathrm{C}(5)$, whereas in the minor Z-isomer, the ethylenic proton at C(9) (5.61 ppm) was correlated with the methyl protons at C(10) (1.77 ppm) only.

\subsection{Cross metathesis of limonene-derived terpenoids with 2-methylbut-2-ene 3}

As was observed with the terpenes 1 and 2, the cross metathesis of the terpenoids $\mathbf{6}$ and 7 with 2-methylbut-2-ene 3 (Scheme 4) were most efficiently achieved under neat conditions with the Hoveyda catalyst Ru2 at $40{ }^{\circ} \mathrm{C}$ (Table 3). The addition of the catalyst in two portions was beneficial with both substrates to reach full conversion. It can be noted that Ru3 showed similar catalytic activity as Ru2 (entry 5), but Ru4 appeared to be less efficient (entry 7). The E/Z ratio for $\mathbf{1 1}$ and $\mathbf{1 2}$ were about 93:7 as determined by GC of the crude reaction mixture. In the ${ }^{1} \mathrm{H}$ NMR of the mixture of inseparable $Z$ - and $E$-stereoisomers of 11, only C(4) exhibited a well separated distinct chemical shift. The major isomer signal was in the range 2.55-2.68, whereas the minor isomer was in the range 3.15-3.38, both of them as multiplets with the same shape. The NOESY experiments showed no interaction between the ethylenic C(9)-H proton (quadruplet at $5.26 \mathrm{ppm}$ ) and the $\mathrm{C}(4)-\mathrm{H}$ centered at $3.25 \mathrm{ppm}$, whereas it was observed with the other isomer with a signal centered at $2.60 \mathrm{ppm}$, confirming the E-stereochemistry of the major product.

For the (+)-trans-limonene epoxide 7 , the best result was obtained at $40{ }^{\circ} \mathrm{C}$ under neat conditions with Ru2 added in two portions corresponding to 2.5 mol\% each (Table 3, entry 6). A conversion of 99\% was obtained and product 12 was isolated in 34\% yield as a mixture of stereoisomers. The GC analysis of the crude mixture of the reaction performed with Ru2 gave an $E / Z$ ratio of $93: 7$, which is comparable to the results obtained with limonene. Ru4 in this case was much less active leading to only $49 \%$ conversion under the same conditions (Table 3 , entry 7). The proton NMR showed the presence of only one major product and it was not possible to identify specific signals of the minor stereoisomer. However, the NOESY spectrum 
indicated an interaction of the ethylenic $\mathrm{C}(9)-\mathrm{H}$ proton (quadruplet at $5.19 \mathrm{ppm}$ ) with the $\mathrm{C}(11) \mathrm{H}_{3}$ methyl group (doublet at $1.54 \mathrm{ppm}$ ) but none with the $\mathrm{C}(10)-\mathrm{H}_{3}$ methyl group appearing as a singlet at $1.52 \mathrm{ppm}$, revealing that the major product was the $E$-isomer.<smiles>C=C(C)[C@H]1CC=C(C)C(=O)C1</smiles>

6<smiles>C=C(C)[C@@H]1CC[C@@]2(C)O[C@H]2C1</smiles><smiles>CC=C(C)C</smiles>

3<smiles>CC=C(C)C</smiles>

Ru cat neat, $40{ }^{\circ} \mathrm{C}, 15 \mathrm{~h}$<smiles>CC=C(C)C1CC=C(C)C(=O)C1</smiles>

11<smiles>CC=C(C)C1CC[C@]2(C)O[C@H]2C1</smiles>

Scheme 4. Cross metathesis of (+)-carvone 6 and (+)-trans-limonene epoxide 7 with 2-methylbut-2-ene 3

Table 3. Cross metathesis of (D)-carvone 6 and (+)-trans-limonene epoxide 7 with 2-methylbut-2-ene $3^{\mathrm{a}}$

\begin{tabular}{|c|c|c|c|c|}
\hline Entry & $\begin{array}{l}\text { Catalyst } \\
\text { (mol\%) }\end{array}$ & Solvent & $\begin{array}{c}\text { Conversion } \\
\text { (\%) }\end{array}$ & $\begin{array}{c}\text { Yield } \\
(\%)\end{array}$ \\
\hline \multicolumn{5}{|c|}{$(+)$-carvone 6} \\
\hline 1 & Ru2 (2.5) & DMC & 82 & 75 \\
\hline 2 & Ru3 (2.5) & DMC & 68 & 61 \\
\hline 3 & Ru2 (5) & Neat & 92 & 86 \\
\hline 4 & $\mathbf{R u} 2(2.5+1)^{\mathrm{b}}$ & Neat & 98 & $95(73)^{c}$ \\
\hline 5 & $\mathbf{R u} 3(2 \times 2.5)^{\mathrm{b}}$ & Neat & 96 & $91(58)^{\mathrm{c}}$ \\
\hline \multicolumn{5}{|c|}{ (+)-trans-limonene epoxide 7} \\
\hline 6 & $\operatorname{Ru} 2(2 \times 2.5)^{b}$ & Neat & 99 & $89(34)^{c}$ \\
\hline 7 & $\operatorname{Ru} 4(2 \times 2.5)^{b}$ & Neat & 49 & 40 \\
\hline
\end{tabular}

a General conditions: terpenoid (100 mg, $0.7 \mathrm{mmol}), 2$-methylbut-2-ene (2.8 mmol in DMC, $9.1 \mathrm{mmol}$ for neat), DMC ( $1 \mathrm{~mL}), 40{ }^{\circ} \mathrm{C}, 15 \mathrm{~h}$, conversion and yield were determined by GC using tetradecane as internal standard. ${ }^{\mathrm{b}}$ first portion $(15 \mathrm{~h})$, second portion $(8 \mathrm{~h}) .{ }^{\mathrm{c}}$ Isolated yield in parenthesis. 


\subsection{Cross metathesis of limonene-derived terpenoids with cis-1,4-dichlorobut-2-ene}

We initially attempted the cross metathesis of the bulky terpenes $\mathbf{1}$ and $\mathbf{2}$ with allyl chloride featuring a terminal double bond but these attempts were unsuccessful. Following the success obtained with the electron deficient dimethyl maleate and the neutral 2-methylbut-2ene, we investigated the behavior of the electronically intermediate cis-1,4-dichlorobut-2-ene (Scheme 5). We attempted the cross metathesis of (-)-limonene 2 with the symmetrical internal olefin cis-1,4-dichlorobut-2-ene at $100{ }^{\circ} \mathrm{C}$ with catalysts Ru2 and Ru3. In DMC or under neat conditions, the conversions of the terpene were very high, reaching 86 and 95\%, respectively. However the GC analysis revealed the presence of numerous products and non-selective transformations. The temperature was thus reduced to $50{ }^{\circ} \mathrm{C}$ and the reactions were performed with catalysts Ru2, Ru3 and Ru4 at 2.5 mol\% catalyst loading in DMC with a twofold amount of 13 or without solvent in the presence of 13 equivalents of $\mathbf{1 3}$. With these cross metathesis partners, the best conditions were obtained in DMC and the conversion after $15 \mathrm{~h}$ reached 6873\% (Table 4, entries 1-3). The conversion was not improved when a second portion of catalyst was added. Under neat conditions, the conversion were located in the range $36-47 \%$ and no beneficial effect was obtained with a higher catalyst loading of $5 \mathrm{~mol} \%$ (Table 4, entries 4-6). The GC analyses of the crude mixture revealed incomplete but clean reactions with only one peak for the new product 14. Similarly the NMR analyses showed the presence of a major stereoisomer with only trace amount of the minor isomer. The new terpene derivative $\mathbf{1 4}$ was difficult to purify by usual chromatography on silica, which led to very low isolated yield, but acceptable results were obtained with elution over alumina. The NOESY spectrum of the isolated product showed that the $\mathrm{C}(11) \mathrm{H}_{2}$ protons with a chemical shift of $4.12 \mathrm{ppm}$ were in strong interaction with the protons of the $\mathrm{C}(10) \mathrm{H}_{3}$ group at $1.72 \mathrm{ppm}$, confirming again in this case the $E$-stereoselectivity of the cross metathesis.

For $(+)$-carvone 6 and $(+)$-trans limonene epoxide 7, the same tendency was observed and it was possible to reach 52 and $68 \%$ conversion, respectively, in DMC at $50{ }^{\circ} \mathrm{C}$ in the presence of 2.5 mol\% of $\mathbf{R u} 2$ (Table 4, entries 7 and 9). Here again, the isolation of the final products proved to be difficult by column chromatography, where partial decomposition was anticipated, may be due to the presence of a chloro group in allylic position. Despite these 
difficulties, samples of the new terpenoids derivatives $\mathbf{1 5}$ and $\mathbf{1 6}$ were isolated in 12 and 15\% yield, respectively.<smiles>C=C(C)[C@H]1CC=C(C)CC1</smiles>

2<smiles>C=C(C)[C@H]1CC=C(C)C(=O)C1</smiles>

6<smiles>C=C(C)[C@@H]1CC[C@@]2(C)O[C@H]2C1</smiles>

Ru cat

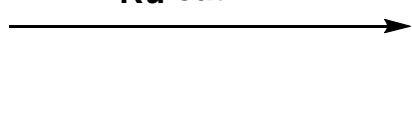

13<smiles>ClC/C=C\CCl</smiles><smiles>[R14]CC</smiles>

13<smiles>ClC/C=C\CCl</smiles><smiles></smiles>

13<smiles>CC(C)=CCCl</smiles><smiles>CC1=CC[C@@H](/C(C)=C/CCl)CC1=O</smiles><smiles>C/C(=C/CCl)[C@@H]1CC[C@@]2(C)O[C@H]2C1</smiles>

Scheme 5. Cross metathesis of (-)-limonene 2, $(+)$-carvone 6, and (+)-trans-limonene epoxide $\mathbf{7}$ with cis-1,4-dichlorobut-2-ene $\mathbf{1 3}$

In both cases, the GC analysis of the crude reaction mixture displayed only one peak for the formed products. Proton NMR did not allow to identify stereoisomers, only in the ${ }^{13} \mathrm{C}$ NMR very small signals could be attributed to a minor isomer. Finally, NOESY experiments suggested that the $E$-isomers were the major products (see SI). These results are in line with our previous observations with cis-1,4-diacetoxybut-2-ene [24]. 
Table 4. Cross metathesis of limonene derivatives with cis-1,4-dichlorobut-2-ene $13^{\mathrm{a}}$

\begin{tabular}{cccccc}
\hline Entry & Catalyst & $\mathbf{1 3} / \mathbf{2}, \mathbf{1 3} / \mathbf{6}$ & Solvent & Conversion & Yield \\
& $(\mathrm{mol} \%)$ & or 13/7 & $(\%)$ & $(\%)$ \\
& molar ratio & & \\
\hline
\end{tabular}

(-)-limonene 2

\begin{tabular}{|c|c|c|c|c|c|}
\hline 1 & Ru2 (2.5) & 2 & DMC & 73 & $35(28)$ \\
\hline 2 & Ru2 $(2 \times 2.5)^{b}$ & 2 & DMC & 69 & - \\
\hline 3 & Ru4 (2.5) & 2 & DMC & 68 & $30(23)$ \\
\hline 4 & Ru2 (2.5) & 13 & Neat & 36 & - \\
\hline 5 & Ru2 (5) & 13 & Neat & 37 & - \\
\hline 6 & Ru3 (2.5) & 13 & Neat & 47 & - \\
\hline \multicolumn{6}{|c|}{$(+)$-carvone 6} \\
\hline 7 & Ru2 (2.5) & 4 & DMC & 52 & $37(12)^{c}$ \\
\hline 8 & Ru2 (5.0) & 13 & Neat & 39 & - \\
\hline \multicolumn{6}{|c|}{ (+)-trans-limonene epoxide 7} \\
\hline 9 & Ru2 (2.5) & 4 & $\mathrm{DMC}$ & 68 & $(15)^{\mathrm{c}}$ \\
\hline 10 & Ru4 (2.5) & 4 & DMC & 64 & - \\
\hline
\end{tabular}

${ }^{a}$ General conditions: terpenoid (100 mg, $\left.0.7 \mathrm{mmol}\right)$, 1,4-dichlorobut-2-ene (1.4 mmol in DMC, $9.1 \mathrm{mmol}$ for neat), DMC ( $1 \mathrm{~mL}), 50^{\circ} \mathrm{C}, 15 \mathrm{~h}$, conversion and yield were determined by GC using tetradecane or hexadecane as internal standard. ${ }^{\mathrm{b}}$ first portion $(15 \mathrm{~h})$, second portion $(8 \mathrm{~h}) .{ }^{\mathrm{c}}$ Isolated yield in parenthesis.

\section{Conclusion}

The strategy developed for cross metathesis of the sterically hindered $\beta$-pinene and (-)-limonene with symmetrical internal olefins such as fumarate, maleate or malonitrile has been extended to the non-symmetrical 2-methylbut-2-ene. With this non-functional trisubstituted alkene, the cross metathesis with second generation ruthenium catalysts provided selectively a new trisubstituted double bond at $40^{\circ} \mathrm{C}$ with high efficacy. The reaction operated better under neat conditions and led to the E-products with very high stereoselectivity. The introduction of oxygenated functionalities such as a ketone or an epoxide in (+)-carvone and 
(+)-trans-limonene epoxide did not inhibit the cross metathesis with any of the cross metathesis partners and the reactivities followed the general rule found for terpenes. For all the metathesis reactions that were investigated, the second generation Hoveyda type catalysts Ru2, Ru3 and Ru4 that are robust and commercially available, exhibited relatively similar reactivities demonstrating the feasibility of these difficult cross metathesis with bulky substrates. For an optimization study, the search for the best catalyst would be necessary. The utilization of internal olefins instead of terminal olefins as cross metathesis partners with bulky cyclic terpenes and terpenoids constitutes an elegant route for the straightforward functionalization of their $\alpha, \alpha$-disubstituted terminal double bond. All cross metathesis products are new compounds and should be evaluated for valuable properties.

\section{Acknowledgements}

The authors acknowledge CAPES-COFECUB for support to the project no. PHC 88417 (France) and 883/2017 (Brazil); D. M. and W. A. C. thank CNPq (project 312288/2019-0 and 404843/2018-2); FAPESP (2018/01258-5, 2017/24931-4 and 2016/05006-5), CAPES (Finance Code 001) and the Multi-User Central Facilities (CEM/UFABC) for the experimental support. Finally, L. S. F. thanks the CAPES-COFECUB grant 88887.144564/2017-00, FAPESP BEPE 2019/18981-4 and FAPESP 2015/26787-2 for scholarships. Umicore is thanked for supplying the ruthenium catalysts M72 (Ru2) and M73 (Ru4).

\section{References}

[1] S. Zwenger, C. Basu, Biotechnol. Mol. Biol. Rev. 3 (2008) 1-7, https://doi.org/10.5897/BMBR2008.0001.

[2] M.H. Alma, T. Salan, Proc. Petrochem. Oil Ref. 18 (2017) 1-12, http://www.ppor.az/jpdf/MehmetHakkiAlma-1(2017).PDF

[3] Industry Report Summary of Limonene Market Size, Price, 2016-2023 https://foreverest.cn/news-list/industry-report-summary-of-limonene-market-size-price-20162023, Posted on 2017/04/19.

[4] W. Schwab, C. Fuchs, F.C. Huang, Eur. J. Lipid Sci. Technol. 115 (2013) 3-8, https://doi.org/10.1002/ejlt.201200157.

[5] K.A.D. Swift, Top. Catal. 2004, 27, 143-155, https://doi.org/10.1023/B:TOCA.0000013549.60930.da 
[6] J.L.F. Monteiro, C.O. Veloso, Top. Catal. 2004, 27, 169-180, https://doi.org/10.1023/B:TOCA.0000013551.99872.8d

[7] N. Ravasio, F. Zaccheria, M. Guidotti, R. Psaro, Top. Catal. 2004, 27, 157-168, https://doi.org/10.1023/B:TOCA.0000013550.28170.6a

[8] M. Malko, A.K. Antosik, A. Wroblewska, Z. Czech, K. Wilpiszewska, P. Miadlicki, B. Michalkiewicz, Pol. J. Chem. Technol. 19 (2017) 50-58, https://doi.org/10.1515/pjct2017-0067.

[9] T. Jacobs, A. Rybak, M.A.R. Meier, Appl. Catal. A: Gen. 353 (2009) 32-35, https://doi.org/10.1016/j.apcata.2008.10.026.

[10] a) X. Miao, P.H. Dixneuf, C. Fischmeister, C. Bruneau, Green Chem. 13 (2011) 22582271, https://doi.org/10.1039/c1gc15377c; b) R. Malacea, C. Fischmeister, C.

Bruneau, J.-L. Dubois, J.-L. Couturier, P.H. Dixneuf, Green Chem. 2009, 11, 152-155, https://doi.org/10.1039/b816917a; c) A. Dupé, M. Achard, C. Fischmeister, C.

Bruneau, ChemSusChem 5 (2012) 2249-2254,

https://doi.org/10.1002/cssc.201200320.

[11] H. Bilel, N. Hamdi, C. Fischmeister, C. Bruneau, ChemCatChem 12 (2020) 5000-5021, https://doi.org/10.1002/cctc.202000959.

[12] C. Bruneau, C. Fischmeister, D. Mandelli, W.A. Carvalho, E.N. dos Santos, P.H. Dixneuf, L. Sarmento Fernandes, Catal. Sci. Technol. 8 (2018) 3989-4004, https://doi.org/10.1039/c8cy01152d.

[13] E. Borré, T.H. Dinh, F. Caijo, C. Crévisy, M. Mauduit, Synthesis 13 (2011) 2125-2130, https://doi.org/10.1055/s-0030-1260605.

[14] H. Bilel, N. Hamdi, F. Zagrouba, C. Fischmeister, C. Bruneau, Green Chem. 13 (2011) 1448-1452, https://doi.org/10.1039/c1gc15024c.

[15] J. Xu, E.J.E. Caro-Diaz, L. Trzoss, E.A. Theodorakis, J. Am. Chem. Soc. 134 (2012) 5072-5075, https://dx.doi.org/10.1021/ja300807e.

[16] H. Bilel, N. Hamdi, F. Zagrouba, C. Fischmeister, C. Bruneau, Catal. Sci. Technol. 4 (2014) 2064-2071, https://doi.org/10.1039/c4cy00315b.

[17] M. Scholl, S. Ding, C.W. Lee, R.H. Grubbs, Org. Lett. 1999, 1, 953-956, https://doi.org/10.1021/ol990909q.

[18] R.T. Mathers, K.C. McMahon, K. Damodaran, C.J. Retarides, D.J. Kelley, Macromolecules 39 (2006) 8982-8986, https://doi.org/10.1021/ma061699h.

[19] Z.I. Wang, W.R. Jackson, A.J. Robinson, Org. Lett. 15 (2013) 3006-3009, https://doi.org/10.1021/ol401194h. 
[20] S.B. Garber, J.S. Kingsbury, B.L. Gray, A.H. Hoveyda, J. Am. Chem. Soc. 122 (2000) 8168-8179, https://doi.org/10.1021/ja001179g.

[21] I.C. Stewart, C.J. Douglas, R.H. Grubbs, Org. Lett. 10 (2008) 441-444, https://doi.org /10.1021/ol702624n.

[22] S. Gutiérrez, M.A. Tlenkopatchev, Polym. Bull. 66 (2011) 1029-1038, https://doi.org/10.1007/s00289-010-0330-X.

[23] A. Martínez, S. Gutiérrez, M.A. Tlenkopatchev, Molecules 17 (2012) 6001-6010, https://doi.org /10.3390/molecules17056001.

[24] L. Sarmento Fernandes, D. Mandelli, W.A. Carvalho, C. Fischmeister, C. Bruneau, Catal. Commun. 135 (2020) 105893, https://doi.org/10.1016/j.catcom.2019.105893.

[25] X. Miao, C. Fischmeister, C. Bruneau, P.H. Dixneuf, ChemSusChem 1 (2008) 813816, https://doi.org/10.1002/cssc.200800074.

[26] A.K. Chatterjee, D.P. Sanders, R.H. Grubbs, Org. Lett. 4 (2002) 1939-1942, https://doi: 10.1021/ol0259793.

[27] a) J. Elaridi, W.R. Jackson, A.J. Robinson, Tetrahedron: Asymmetry 16 (2005) 20252029, https://doi:10.1016/j.tetasy.2005.05.003; b) B.J. van Lierop, W.R. Jackson, A.J. Robinson, Tetrahedron 66 (2010) 5357-5366, https://doi:10.1016/j.tet.2010.05.068.

[28] a) S.O. Simonetti, E.L. Larghi, T.S. Kaufman, Org. Biomol. Chem., 14 (2016) 26252636, https://doi: 10.1039/c5ob02680f; b) C. Schultze, S. Foß, B. Schmidt, Eur. J. Org. Chem. (2020) 7373-7384, https://doi.org/10.1002/ejoc.202001378; c) G. Kwesiga, A. Kelling, S. Kersting, E. Sperlich, M. von Nickisch-Rosenegk, B. Schmidt, J. Nat. Prod. 83 (2020) 3445-3453, https://dx.doi.org/10.1021/acs.jnatprod.0c00932; d) C. Schultze, B. Schmidt J. Org. Chem. 83 (2018) 5210-5224, https://doi: 10.1021/acs.joc.8b00667; e) J. Magolan, M.J. Coster, J. Org. Chem. 74 (2009) 50835086, https://doi : 1 0.1021/jo900613u.

[29] a) S. Tischer, P. Metz, Adv. Synth. Catal. 349 (2007) 147- 151, https://doi: 10.1002/adsc.200600454; b) P. Pahari, J. Rohr, J. Org. Chem. 74 (2009) 2750-2754, https://doi: 10.1021/jo8025884.

[30] A. Sytniczuk, A. Kajetanowicz, K. Grela, Catal. Sci. Technol. 7 (2017) 1284-1296, https://doi: 10.1039/c6cy02623k.

[31] R.R. Sapkota, J.M. Jarvis, T.M. Schaub, M.R. Talipov, J.B. Arterburn, ChemistryOpen 8 (2019) 201-205, https://doi: 10.1002/open.201800296.

[32] M. Ulman, T.R. Belderrain, R.H. Grubbs, Tetrahedron Letters 41 (2000) 4689-4693, https://doi.org/10.1016/S0040-4039(00)00696-1. 
[33] a) T. Ritter, A. Hejl, A.G. Wenzel, T.W. Funk, R.H. Grubbs, Organometallics 25 (2006) 5740-5745, https://doi.org/10.1021/om060520o; b) D.R. Anderson, T. Ung, G. Mkrtumyan, G. Bertrand, R.H. Grubbs, Y. Schrodi, Organometallics 27 (2008)563566, https://doi.org/10.1021/om7008028.

[34] D. Rix, F. Caijo, I. Laurent, F. Boeda, H. Clavier, S.P. Nolan, M. Mauduit, J. Org. Chem. 73 (2008) 4225-4228, https://doi.org/10.1021/jo800203d. 